\title{
Belajar Bermakna (Meaningful Learning) Ausubel Menggunakan Model Pembelajaran dan Evaluasi Peta Konsep (Concept Mapping) Untuk Meningkatkan Kemampuan Pemahaman Konsep Mahasiswa Calon Guru Sekolah Dasar Pada Mata Kuliah Konsep Dasar IPA
}

Tarmidzi ${ }^{1}$

1)Universitas Swadaya Gunung Jati, jl. Perjuangan No.1 Cirebon; mulyatarmidzi@gmail.com

Abstrak. Belajar bermakna (Meaningful Learning) yang dicetuskan oleh David Ausubel merupakan suatu proses dikaitkannya informasi-informasi baru dengan konsepkonsep yang relevan yang terdapat dalam struktur kognitif seseorang (Dahar dalam Trianto, 2007: 25). Peta konsep dimaksudkan untuk mewakili hubungan antar konsep yang bermakna dalam bentuk proposisi (Novak \& Gowin, 1984: 15). Penelitian ini bertujuan untuk mengetahui kemampuan pemahaman konsep mahasiswa sebelum dan sesudah pembelajaran menggunakan model peta konsep. Hasil penelitian ini diharapkan dapat memberikan manfaat sebagai tambahan pengetahuan mengenai model-model pembelajaran agar dapat digunakan sendiri sebagai sarana belajar guna meningkatkan pengetahuan dan/atau sebagai tambahan referensi cara mengajar agar di kemudian hari dapat digunakan di sekolah dasar. Penelitian ini merupakan penelitian eksperimen lemah yang desain dan perlakuannya seperti eksperimen tetapi tidak ada pengontrolan variabel sama sekali dengan subjek penelitian sebanyak 30 orang (33\%) mahasiswa Prodi PGSD FKIP Unswagati Cirebon dan desain penelitian yang digunakan adalah Pre-test and Post-test Group Design. Hasil pengujian perbedaan menggunakan Uji T Sampel Berpasangan menunjukkan bahwa terdapat perbedaan pemahaman konsep mahasiswa antara sebelum dan setelah pembelajaran menggunakan model pembelajaran peta konsep.

Kata Kunci: Belajar Bermakna, Peta Konsep, dan Pemahaman Konsep

Abstract. Meaningful Learning initiated by David Ausubel is a process of linking new information with relevant concepts contained in a person's cognitive structure (Dahar in Trianto, 2007: 25). Concept maps are intended to represent meaningful relationships between 
concepts in the form of propositions (Novak \& Gowin, 1984: 15). This study aims to determine the ability of students to understand concepts before and after learning using the concept map model. The results of this study are expected to provide benefits as additional knowledge about learning models so that they can be used alone as a learning tool to increase knowledge and / or as an additional reference for teaching methods so that later they can be used in primary schools. This research is a weak experimental study whose design and treatment is like an experiment but there is no control of the variables at all with the research subjects of 30 people $(33 \%)$ PGSD FKIP Unswagati Study Program students in Cirebon and the research design used is Pre-test and Post-test Group Design. The results of testing the differences using the Paired Sample T Test showed that there were differences in students' understanding of concepts between before and after learning using the concept map learning model.

Keywords: Meaningful Learning, Concept Maps, and Understanding Concepts

\section{Pendahuluan}

Belajar bermakna (Meaningful Learning) yang dicetuskan oleh David Ausubel merupakan suatu proses dikaitkannya informasi-informasi baru dengan konsep-konsep yang relevan yang terdapat dalam struktur kognitif seseorang (Dahar dalam Trianto, 2007: 25). Sehingga perubahan akan dihasilkan dalam struktur kognitif siswa, konsep pengetahuan siswa termodifikasi dan jaringan pengetahuan baru akan terjadi, hal ini merupakan alat yang tepat guna memungkinkan terjadinya pembelajaran yang sebenarnya, yang mampu menghasilkan daya ingat dan penyimpanan pengetahuan yang lebih baik pada siswa dan memfasilitasi perpindahan pengetahuan pada situasi nyata lainnya (Vallori, 2014: 199). Beberapa hal yang dapat menciptakan pembelajaran bermakna diantaranya adalah model pembelajaran dan pemahaman konsep guru terhadap materi yang akan disampaikan. Pemahaman konsep guru adalah salah satu komponen penting untuk menciptakan pembelajaran bermakna (meaningful learning) di kelas. Guru akan mampu memfasilitasi dan membantu siswa dalam belajar jika pemahaman guru terhadap suatu konsep cukup baik. Salah satu alternatif model yang dapat digunakan guna menghasilkan pembelajaran yang bermakna adalah dengan penerapan model pembelajaran peta konsep (concept mapping). Peta konsep adalah alat grafis yang mengorganisasi, menghubungkan, dan menyatukan berbagai informasi (Kilic \& Cakmak, 2013: 153). Peta konsep dimaksudkan 
untuk mewakili hubungan antar konsep yang bermakna dalam bentuk proposisi (Novak \& Gowin, 1984: 15). Proposisi sendiri didefinisikan sebagai dua atau lebih nama konsep dihubungkan dengan kata yang memiliki arti terkait. Pembelajaran dengan peta konsep dapat membuat siswa menjadi aktif, mandiri, berpikir, mempunyai rencana, kooperatif, dan bertanggungjawab (Cano et. al., 2013: 16). Peta konsep telah sukses digunakan pada berbagai disiplin ilmu, karena peta konsep dapat menguntungkan siswa karena tidak hanya mampu meningkatkan kapasitas siswa dalam belajar cara belajar tetapi juga dapat membuat siswa mampu mengaitkan dan menggabungkan pengetahuan yang baru dengan pengetahuan yang telah dimiliki siswa (meaningful learning) (Chiou, 2008: 385). Konsep-konsep menyediakan skemaskema terorganisasi untuk mengasimilasikan stimulus-stimulus baru, dan untuk menentukan hubungan di dalam dan diantara kategori-kategori (Tarmidzi, 2010: 25). Konsep adalah merupakan ide atau pengertian yang diabstrakkan. Konsep-konsep merupakan dasar bagi proses-proses mental yang lebih tinggi untuk merumuskan prinsip-prinsip dan generalisasigeneralisasi. Konsep adalah suatu proses pemusatan perhatian seseorang pada situasi tertentu dari serangkaian pengalaman yang didefinisikan sebagai suatu kelompok benda atau kejadian (Carrol dalam Al-Tabany, 2014:185; Suci, 2016: 7). Novak (Cano et. al., 2013: 16) menyatakan beberapa unsur peta konsep sebagai berikut.

1. Konsep. Konsep dipahami sebagai kata atau kondisi yang menggambarkan keteraturan dalam fakta, kejadian, ide, dan/atau kualitas.

2. Proposisi. Proposisi disusun dari penggabungan dua atau lebih konsep yang dihubungkan oleh kata sambung dalam kesatuan arti. Dihubungkan dengan kesatuan makna utama.

3. Kata sambung. kata sambung adalah kata yang menghubungkan konsepkonsep dan mengidentifikasi tipe hubungan antar konsep tersebut.

Adapun langkah-langkah untuk memperkenalkan peta konsep pada mahasiswa (Novak dan Gowin, 1984:32-33) adalah sebagai berikut.

1. Aktivitas untuk mempersiapkan peta konsep 
a. Buat dua daftar kata yang mudah dikenali, yang pertama merupakan kata benda, kedua merupakan kata kejadian, lalu tanyakanlah pada mahasiswa apakah mereka mengetahui perbedaan dari kedua daftar kata tersebut. Bantulah mereka untuk mengenali bahwa daftar kata yang pertama adalah menunjukkan benda atau objek dan daftar kata kedua menunjukkan kejadian, lalu berilah label pada kedua daftar kata tersebut.

b. Mintalah mahasiswa untuk menjelaskan apa yang ada dalam pikiran mereka ketika mendengar kata benda, seperti hewan, tumbuhan, dan lainlain. Bantu mereka memahami bahwa meskipun kita menggunakan kata yang sama tetapi apa yang kita pikirkan atau bayangkan mungkin saja berbeda. Bayangan kita terhadap kata tersebut adalah "konsep"; kenalkanlah kata konsep.

c. Ulangi aktivitas kedua, kali ini menggunakan kata kejadian. Sekali lagi, Minta mahasiswa untuk menjelaskan apa yang ada dalam pikiran mereka ketika mendengar kata kejadian. Sambil mengajarkan dengan kata yang sama kita memiliki konsep yang berbeda.

d. Bantu mahasiswa untuk mengenali kata sambung seperti, dimana, yang, dari, dengan, dan adalah.

e. Mahasiswa dapat membedakan antara kata benda dan kata kejadian secara spesifik.

f. Gunakan beberapa contoh untuk membantu mahasiswa membedakan antara kata kejadian dan kata benda.

g. Minta mahasiswa untuk membuat kalimat sederhana, kemudian minta mereka untuk membedakan mana yang merupakan kata konsep dan identifikasi kalimat tersebut.

h. Perkenalkan kata asing kepada mahasiswa, walaupun kata-kata tersebut mereka sudah tahu. Bantu mahasiswa untuk mengenalkan arti sebuah konsep bisa berubah tergantung konteks kalimat.

i. Pilih bagian dari teks buku (1 halaman) yang di copy lalu bagikan ke mahasiswa. Perintahkan mahasiswa menjelaskan beberapa kata sambung (membedakan antara kata konsep dan kata pemghubung).

2. Aktivitas peta konsep

Caruban: Jurnal Ilmiah Pendidikan Dasar 1(2), 131-140, Juli 2018

p-ISSN 2615-1391, e-ISSN 2620-3219 @Prodi PGSD Universitas Swadaya Gunung Jati 
a. Pilih sebuah paragraf yang memiliki arti, minta mahasiswa untuk membaca dan memilih kata kunci, tuliskan di papan tulis dan diskusikan dengan mahasiswa lain kata konsep dari yang paling khusus sampai yang paling umum.

b. Simpan konsep yang paling utama didaftar yang paling atas, lalu peringkatkan sampai konsep yang paling umum.

c. Sekarang mulailah membangun peta konsep secara hirarki. Bantu mahasiswa membuat kata sambung yang sesuai.

d. Lihatlah garis silang antar konsep dalam sebuah peta, dan buat kata sambung.

e. Mahasiswa mengulang pembuatan peta konsep sampai tiga kali, setiap mahasiswa mengulang pembuatan peta konsep, mereka akan mendapat hasil yang lebih baik dibandingkan pembuatan peta konsep awal atau sebelumnya.

f. Beritahu mahasiswa contoh untuk memberi skor dalam pembuatan peta konsep.

g. Setelah memberi satu bagian dari teks, biarlah mahasiswa mengulangi langkah 1-6.

h. Mahasiswa mempresentasikan pembuatan peta konsep dengan jelas.

Menurut Novak \& Gowin (1984: 36) kriteria penskoran untuk peta konsep sebagai berikut.

1. Proporsi. Menghubungkan dua konsep makna yang ditunjukkan oleh garis yang menghubungkan dan kata penghubung, merupakan hubungan yang valid. Skor 1 poin.

2. Hirarki. Setiap konsep yang berada di atas adalah konsep umum dan konsep yang dibawah yang mengikutinya merupakan konsep yang lebih spesifik. Skor 5 poin untuk setiap level yang valid dan hirarki.

3. Garis silang. Menunjukkan adanya hubungan yang bermakna antara satu konsep di suatu segmen yang hirarki dengan segmen lain. Jika garis silang tersebut tepat menghubungkan, maka skor yang diperoleh 10 poin untuk setiap garis silang dan skor 2 poin jika garis silang yang menghubungkan tidak tepat. 
4. Contoh. Pada peristiwa atau benda tertentu yang sesuai contoh yang ditunjukkan oleh tiap konsep masing-masing mendapat 1 poin.

\section{Metode Penelitian}

Penelitian ini bertujuan untuk melihat perbedaan kemampuan pemahaman konsep mahasiswa antara sebelum dan sesudah pembelajaran menggunakan model peta konsep, pada mahasiwa diterapkan perlakuan tanpa pengontrolan variabel sama sekali. Penelitian eksperimen yang desain dan perlakuannya seperti eksperimen tetapi tidak ada pengontrolan variabel sama sekali disebut dengan metode penelitian Eksperimen Lemah (Weak Experiment) (Syaodih, 2005: 59). Subjek dalam penelitian ini adalah sebanyak 29 orang (33\%) mahasiswa Prodi PGSD FKIP Unswagati Cirebon. Desain penelitian yang digunakan adalah Pre-test and Post-test Group Design (Arikunto, 2010: 124).

\section{Hasil Penelitian dan Pembahasan}

Berdasarkan hasil uji pemahaman konsep yang telah dilaksanakan sebelum (pra tes) dan setelah (pasca tes) pembelajaran, maka nilai rerata pemahaman konsep mahasiswa dapat dilihat pada Gambar 1.

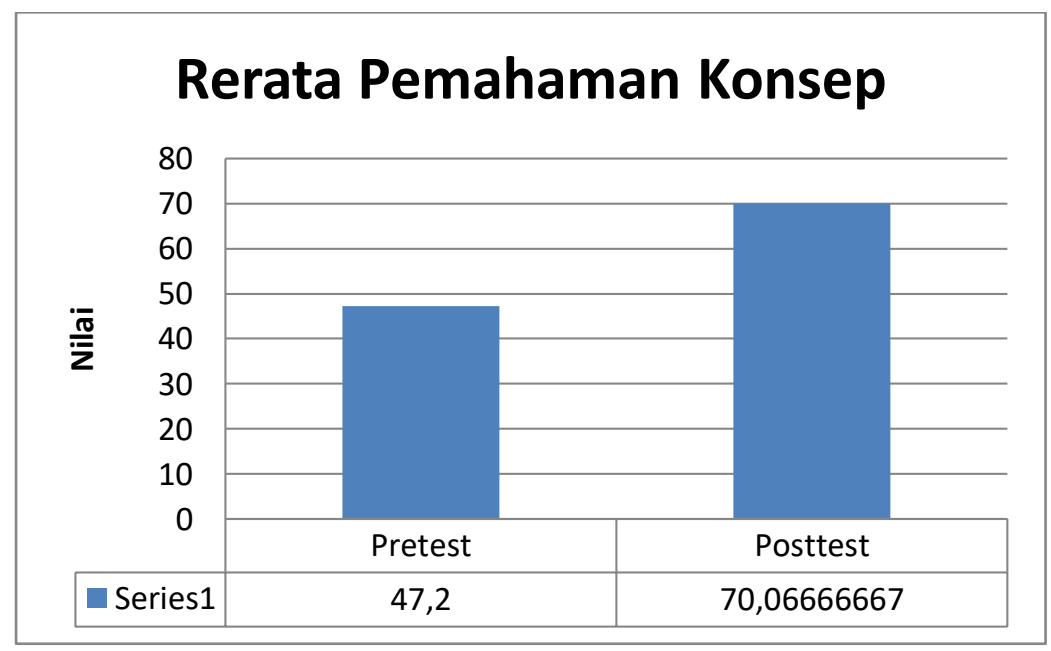

Gambar 1 Rerata Pemahaman Konsep Mahasiswa 
Secara personal, data pemahaman konsep mahasiswa dapat disajikan seperti pada Gambar 2 berikut.

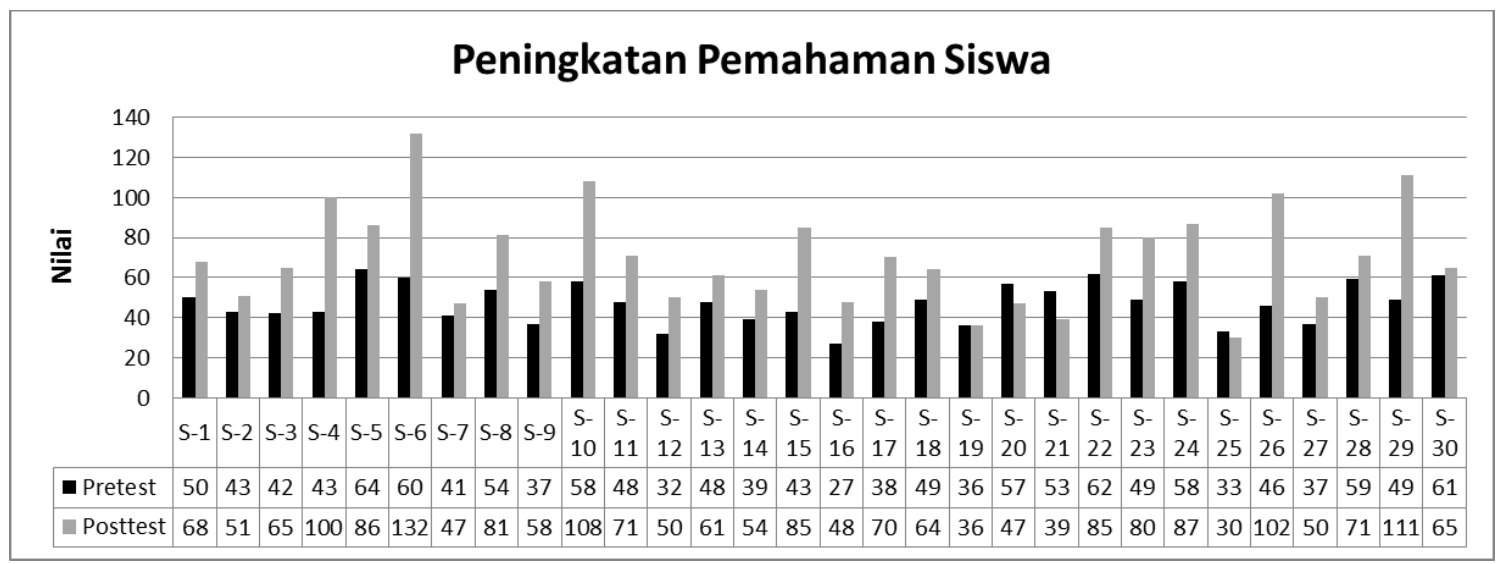

Gambar 2. Peningkatan Pemahaman Konsep Mahasiswa

Berdasarkan hasil Uji T Sampel Berpasangan, didapatkan data seperti dapat dilihat pada Tabel 1 berikut.

Tabel 1 Uji T Sampel Berpasangan

\section{Paired Differences}

\begin{tabular}{|c|c|c|c|c|c|c|c|c|c|}
\hline & & \multirow[t]{2}{*}{ Mean } & \multirow[t]{2}{*}{$\begin{array}{l}\text { Std. } \\
\text { Deviati } \\
\text { on }\end{array}$} & \multirow[t]{2}{*}{$\begin{array}{l}\text { Std. } \\
\text { Error } \\
\text { Mean }\end{array}$} & \multicolumn{2}{|c|}{$\begin{array}{l}\text { 95\% Confidence } \\
\text { Interval of the } \\
\text { Difference }\end{array}$} & \multirow[t]{2}{*}{$\mathrm{t}$} & \multirow[t]{2}{*}{$\mathrm{df}$} & \multirow[t]{2}{*}{$\begin{array}{l}\text { Sig. (2- } \\
\text { tailed) }\end{array}$} \\
\hline & & & & & Lower & Upper & & & \\
\hline Pair 1 & $\begin{array}{l}\text { Pretest - } \\
\text { Posttest }\end{array}$ & -22.867 & 20.761 & 3.790 & -30.619 & -15.114 & -6.033 & 29 & .000 \\
\hline
\end{tabular}

Pada Tabel di atas, kita dapat nilai Sig. (2-Tailed) sebesar 0,000 (Sig. $<\alpha=$ 0,05), sehingga $\mathrm{H}_{1}$ diterima dan $\mathrm{H}_{0}$ ditolak dan kita dapat menyatakan bahwa terdapat perbedaan pemahaman konsep mahasiswa antara setelah belajar dan sebelum belajar menggunakan model peta konsep.

\section{Simpulan dan Rekomendasi}

Berdasarkan hasil penelitian yang dilaksanakan, penulis dapat mengambil beberapa kesimpulan, yakni (1) Kemampuan mahasiswa dalam 
membat peta konsep yang memperlihatkan kemampuan pemahaman konsep mereka masih terlihat sangat kurang. Rata-rata siswa belum paham apa yang dimaksud dengan konsep dan kata sambung serta membuat proposisi antar konsep dengan menggunakan kata sambung. Mahasiswa pun belum mampu memberi contoh yang baik pada tiap konsep serta belum mampu membuat garis silang (cross link) yang menghubungkan antar segmen; (2) Kemampuan mahasiswa dalam membuat peta konsep yang menggambarkan kemampuan pemahaman konsep mereka sudah terlihat lebih baik, hal ini terlihat dari semakin kompleksnya peta konsep yang berhasil mereka buat. Mahasiswa sudah mampu mengidentifikasi konsep dan kata sambung. Mahasiswa sudah mampu menghubungkan antar konsep dengan kata sambung (proposisi), mahasiswa juga sudah mampu memberi contoh yang baik pada beberapa konsep. Kekurangan mahasiswa dalam pasca tes ini adalah belum ada mahasiswa yang mampu membuat cross link antar segmen dalam peta konsep; dan (3) Terdapat peningkatan kemampuan pemahaman konsep mahasiswa yang dibuktikan dengan hasil uji statistika menggunakan Uji T Sampel Berpasangan. Hal ini menunjukkan efektivitas pembelajaran menggunakan model peta konsep dalam meningkatkan kemampuan pemahaman mahasiswa terutama dalam mata kuliah Konsep Dasar IPA. Betdasarkan hal tersebut kita dapat menyimpulkan bahwa model pembelajaran peta konsep mampu meningkatkan kemampuan pemahaman konsep mahasiswa.

\section{Daftar Pustaka}

Akdon. (2008). Aplikasi Statistika dan Metode Penelitian untuk Administrasi dan Manajemen. Dewa Ruchi. Bandung Barat.

Anderson, L., W \& Krathwohl. (2001). Taxonomy for Learning, Teaching, and Assessing. A revision of Bloom's Taxonomy of Educational Objectives. New York: Addison Wesley Longman,Inc.

Arikunto, S. (2010). Prosedur Penelitian. Suatu Pendekatan Praktik. Rineka Cipta. Jakarta.

Asan, A. (2007). Concept Mapping in Science Class: A Case Study of Fifth Grade Students. Educational Technology \& Society, 10 (1), 186-195. 
Brinkerhoff, J. L. \& Booth, G. M. (2013). The Effect of Concept Mapping On Student Achievement in An Introductory Non-Majors Biology Class. European International Journal of Science and Technology. 2 (8).

Chiou, C. C. (2008). The effect of concept mapping on students' learning achievements and interests. Innovations in Education and Teaching International. 45( 4), 375387

Dahar, R., W. (1996). Teori-teori Belajar. Jakarta: Erlangga

Eggen, P. \& Kauchak, D. (2012). Strategi dan Model Pembelajaran. Mengajarkan Konten dan Keterampilan Berpikir. Jakarta: Indeks.

Joyce, M., Weil, M., Calhoun, E., (2009). Models of Teaching. Model-model Pengajaran. Yogyakarta: Pustaka Pelajar.

Karakuyu, Y. (2010). The effect of concept mapping on attitude and achievement in a physics course. International Journal of the Physical Sciences. 5(6),724-737, Available online at http://www.academicjournals.org/IJPS ISSN 1992 - 1950 C 2010 Academic Journals.

Kilic, M., \& Cakmak M. (2013). Concept Map As A Tool For Meaningful Learning and Teaching in Chemistry Education. International Kournal on New Trends in Education and Their Implications. Volume: 4 Issue: 4 Article: 14. ISSN: 13096249.

Marhendri. (2007). Model Pembelajaran Inkuiri Terbimbing pada Materi Keseimbangan Benda Tegar untuk Meningkatkan Penguasaan Konsep dan Keterampilan Generik Sains Siswa SMA. Tesis pada Sekolah Pascasarjana Universitas Pendidikan Indonesia Bandung: tidak diterbitkan.

Novak, J. D. (2011). A Theory of Education: Meaningful Learning Underlies The Construcive Integration of Thinking, Feeling and Acting Leading To Empowerment for Commitment and Responsibility. Aprendizagem Significativa em Revista/Meaningful Learning Review - V1(2), pp. 1-14.

Novak, J. D. \& Gowin, D. B. (1984). Learning How To Learn. United States of America: Cambridge University Press

Syaodih, N., (2005). Metode Penelitian Pendidikan. Bandung: Remaja Rosdakarya

Trianto. (2007). Model-model Pembelajaran Inovatif Berorientasi Konstruktivistik. Konsep, Landasan Teoretis - Praktid dan Implementasinya. Jakarta: Prestasi Pustaka Publisher.

Vallori, A. B. (2014). Meaningful Learning in Practice. Journal of Education and Human Development, 3(4), 199-209 ISSN: 2334-296X (Print), 2334-2978 (Online).

Yusuf, S. (2007). Buku Materi Pokok Pedagogik Pendidikan Dasar. Bandung: Sekolah Pascasarjana. Universitas Pendidikan Indonesia 